\title{
The Religious Effects of Metaphors of Songs and Lyrics in Dunhuang Buddhism*
}

\author{
Yanghe Wang \\ The College of Literature and Journalism \\ Sichuan University \\ Chengdu, China
}

\begin{abstract}
The religion is closely related to art. Among the Buddhist books, the metaphorical technique, one of the language arts, is more prominent. There are 823 Buddhist songs including 228 metaphorical words (not counting repeated metaphorical words) in Summary of Dunhuang Songs and Lyrics of REN Zhongmin. From the perspective of rhetoric, the use of the metaphor can make the language vivid, concise and comprehensive. In the spread of Buddhism, the use of metaphor highlights the core concepts of Buddhism and can effectively attract believers. The metaphor highlights and shapes the Buddhist images of "beauty and nobility", "kindness" and "freedom from suffering".
\end{abstract}

Keywords-Dunhuang songs and lyrics; metaphor; rhetoric; spread

\section{INTRODUCTION}

In the world, various religions mostly use art to spread and expand their influence, such as religious architectural art, engraving art, painting art, music art, literature and other forms. Hegel once said that "art is directly connected with religion at its highest level" ${ }^{1}$. Religion often uses art to make us feel its truth better. ${ }^{2}$ There is the concept of apadana in the Buddhist language ${ }^{3}$, which has caused a lot of attention and been widely used in the Buddhist books of all ages. To make it easy for people to understand the content of the meaning of teaching and speaking, the use of examples or fables to illustrate is known as apadana. ${ }^{4}$ In Hinayana Buddhism, such as One Hundred Buddhist Parables and The Miscellaneous Hundred Buddhist Parables make full use of apadana stories to illustrate Buddhist principle. In Mahayana Buddhism, the Mahayana Mahaparinirvana Sutra lists the similes of sequent simile, obsequent simile, non-simile, etc. In the Diamond Sutra,

*This paper is part of the humanities and social science research project of Sichuan Provincial Department of Education (Project number: 17SB0444).

MA Delin, Religion, a Cultural Phenomenon [M], Shanghai People's Publishing House, in the year of 1987, Page 101

MA Delin, Religion, a Cultural Phenomenon [M], Shanghai People's Publishing House, in the year of 1987, Page 102

MA Delin, Religion, a Cultural Phenomenon [M], Shanghai People's Publishing House, in the year of 1987, Page 105

4 Hong Xue, Buddhist Literature of Chinese Language Family [M], Bashu Book, in the year of 2006, Page 14
"All conditioned occurrences, like the morning dew, or like lightning "is a famous serial simile. Kumarajiva also wrote the Poem of Ten Metaphors, which showed that everthing was illusions and things hanppened with phantom simile, sunshine simile and so on. And the figure of apadana is more prominent in the Dunhuang Buddhism songs and lyrics of the Mahavairocana Sutra, the Mahaprajnaparamita Upadesha and Vimalakirti Sutra. There is a deep study on the apadana of Buddhist books in A Study on the Theory of Buddhist Apadana of Liu Zhengping, Meditation and Apadana - Discuss a difference between Chinese Zen and Indian Buddhism of Zhang Jiemo and Apadana: Convenient Transmission and Poetic Expression for Buddhism of Zhang Shahai. Apadana has a profound meaning in Buddhism. The apadana of Sanskrit means taking the known thing reveals the unknown thing in Buddhism Dictionary. Saddharmapundarika Sentences: an apadana is showing a example and giving a lesson; say one thing but mean more things; the example is simple, but the lesson is impressive. The apadana has a variety of meanings, including rhetoric, illustration, reasoning and other composite meanings. (Liu Zhengping, 2010) this paper mainly analyzes metaphoric words in Buddhist songs and lyrics from the perspective of metaphor vocabulary. ${ }^{5}$ This paper mainly takes the Buddhist songs and lyrics in Summary of Dunhuang Songs and Lyrics of Ren Zhongmin as the research object to explore the application of the metaphoric words of Buddhism. Buddhism uses folk popular music literature forms such as Quzici to spread Buddhism and express the "love" of the Buddha. "This kind of love forms an emotional communication between god and human beings, and music is the most appropriate expression of this emotion." ${ }^{6}$ The spread of these Buddhist literature forms, which affected

Metaphor is a general term of concepts which different scholars have different classifications of. For example, Black (1979) is divided into extinct metaphor and latent metaphor (active metaphor), and L\&J is divided into structural metaphor, directional metaphor and ontological metaphor. There are also dominant metaphor (simile), allusive metaphor (metaphor), root metaphor, derivative metaphor and so on. This paper focuses on the analysis of rhetorical effect, so it won't go into details about the distinctions of the metaphor.

6 MA Delin, Religion, a Cultural Phenomenon [M]. Shanghai People's Publishing House, in the year of 1987, Page 120 
Chinese culture, was one of the great cultural exchanges in world history. $^{7}$

The songs and lyrics analyzed in this paper are combined with the Checked Summary of Dunhuang Songs and Lyrics of Xiang Chu, First Revisal of Dunhuang Lyrics of Jiang Lihong, The Collection of Dunhuang Quzici of Wang Chongmin, Dunhuang Melody of Rao Zongyi, New Book of Dunhuang Yunyao Collection and Miscellaneous Melodies of Pan Zhonggui, as well as the proofreading by Long Hui, Zeng Liang and other scholars. The Summary of Dunhuang Songs and Lyrics includes 1,248 Dunhuang songs and lyrics, of which Buddhist couplet lyrics account for a large part. They are mainly divided into two categories: "Buddhists use them for internal restraint and self-restraint" and "external ones use them to deceive people". Among them, there are 5 pieces of Miscellaneous Melody - Ziqu, 208 pieces of Buddhist melody in Ordinary Couplet (plus 7 pieces of Echo Music, Separate from the Confusion and 2 pieces of Hidden), 163 pieces of Buddhist melody in Double Sentences Couplet, 313 pieces of Buddhist melody in Fixed Couplet and 134 pieces of Buddhist melody in Long Fixed Couplet. The total number of Buddhist melodies is 823 .

\section{METAPHORIC WORDS OF BUDDHISM}

Metaphor is widely used in Dunhuang songs and lyrics and Buddhist melodies, such as sentences of the Difficult to Walk on the Road No Heart Rhythm: "Difficult to walk on the road, difficult to walk on the road, as the requirement of the father, I have to transfer excrement early." The transferring excrement is the excrement transportation, which is common metaphoric words in Buddhist books and comes from the sentence of Saddharmapundarika Sutra - Explanation for Shinge: "Looking for someone in Qihua Town, and tell him to get paid for excrement transportation". The sentence shows that the payment of excrement transportation is an apadana of Buddhism in Hinayana Buddhism and expresses the thought of three realms through the small things. Another example is "sheep, deer, and cattle". Saddharmapundarika Sutra Explanation for Apadana uses sheep, deer, and cattle to refer to the three vehicles of Sound-Hearer, Pratyekabuddha, and Bodhisattva by apadana. Buddhism believes that these three vehicles can help people get rid of the fire of samsara. According to the internal structure of metaphoric words, they can be divided into the foregoing metaphor, the latter metaphor and the complete metaphor. Due to the limitation of space, only statistics are made here. Metaphors of each category will not be listed one by one. (This paper makes an exhaustive statistics on metaphoric words in REN's summary. The number of the words is given in appendix without repeated ones. )

Hong Xue, Buddhist Literature of Chinese Language Family [M], Bashu Book, in the year of 2006, Page 4
TABLE I. CATEGORY OF METAPHORICAL WORDS IN BUDDHISM

\begin{tabular}{|l|l|l|l|}
\hline Category & $\begin{array}{l}\text { The } \\
\text { Foregoing } \\
\text { Metaphor }\end{array}$ & \multicolumn{1}{|c|}{$\begin{array}{c}\text { The Latter } \\
\text { Metaphor }\end{array}$} & \multicolumn{1}{|c|}{$\begin{array}{l}\text { The Complete } \\
\text { Metaphor }\end{array}$} \\
\hline $\begin{array}{l}\text { For } \\
\text { example }\end{array}$ & $\begin{array}{l}\text { Moon face, } \\
\text { wind and fire } \\
\text { nature, } \\
\text { ignorance } \\
\text { mouth }\end{array}$ & $\begin{array}{l}\text { Bodhi seed, } \\
\text { Bodhi merit }\end{array}$ & $\begin{array}{l}\text { Medicine King, } \\
\text { Regulating Hero, } \\
\text { Dharma King } \\
\text { (Dharmaraja) }\end{array}$ \\
\hline Quantity & 3 & 77 & 148 \\
\hline
\end{tabular}

From the above statistics (see "Table I"), we can see some metaphoric words in Buddhist books. In terms of content, there are a large number of metaphoric words about nirvana, wisdom, worry, ignorance, living, life and death, and secular, as well as Buddhist theories. This shows that most of these metaphoric words are closely related to Buddhist concepts and theories and serve to express Buddhist thoughts. In terms of word formation, there are 148 complete metaphoric words which are the most. The latter metaphoric words are the second most with the number of 77 . That is the general construction pattern of Buddhist metaphoric words. The foregoing metaphoric words are the least with the number of 3 .

Lakoff and Johnson believe that metaphor is to understand the experience of one field from the experience of another one. Metaphor is not only a linguistic phenomenon but also a tool for people to understand the perception and form concepts of the external world. The cognitive model can be summarized into the following aspects: $\mathrm{O} \rightarrow \mathrm{C} \rightarrow \mathrm{E}(\mathrm{O}=$ ontology, $\mathrm{E}=$ epistemology, $\mathrm{C}=$ cognition $)^{8}$, which means people perceive and understand the objective world through cognition. Langacker believes that it can be described in detail from the aspects of "detail, scope, background, perspective and prominence" to cognize the world. ${ }^{9}$ Based on the theory of Idealized Cognitive Models proposed by Lakoff (1987), this paper analyzed the metaphoric words in Buddhist songs and lyrics. This theory is an important cognitive method to study human conceptual structure and semantic category. Cognitive model refers to human's psychological construction of the objective world. Cognitive model is an idealized and abstract model. Its purpose is not to represent the external world accurately, but to understand experience in a normative way ${ }^{10}$ (Wang Wenbin, 2014). Lakoff believed that human beings often organize knowledge and represent reality by structure, and each ICM is a complex structural entirety and gestalt. In short, ICM is the human's abstract generalization for objective reality and the embodiment of human's cognitive psychological structure. CM is the cognitive mode formed on the basis of the interaction between human and the external world, and the way in which human beings

8 Zhao Yanfang, An Introduction to Cognitive Linguistics [M], Shanghai Foreign Language Education Press, in the year of 2009, Page 99.

Wen Suolin, The Existential Sentences to Cognitive Basis and Rhetorical Motivation of Spatial Metaphor, Shanghai University Press, in the year of 2008, Page 82 .

10 Wang Wenbin, The Nature, Structural Types and Internal Relations of the Idealized Cognitive Models, Foreign Language Learning Theory and Practice, in the year of 2014, the third issue. 
organize and summarize knowledge ${ }^{11}$ (Zhao Yanfang 2000). The foreign scholars of Lakoff (1987), Croft\&Cruse (2004), Cienki (2007) and domestic scholars of Zhao Yanfang (2001), Chen Zhong (2006) and Wang Yin (2012) ${ }^{12}$ have all discussed this topic deeply, so this paper won't do it here. ICM mainly includes four models: proposition, imageschema, metaphor, and metonymy \& symbol. Such as Nirvana metaphor series, to analyses its metaphoric projection relations.

Niepan was Hindi, said Nirvana, and has been translated as Nihuan or Nifunan as well. Its meaning includes Mie, Ji, Jimie, Jijing, Miedu, which is translated as Yuanji (Death of monk) by Xuanzang. Nirvana is rich in its connotation. The Mahayana Mahaparinirvana Sutra lists 25 meanings of it in total. It is the ultimate goal for Buddhists' learning and has a profound impact on Buddhists. The projection relation of the metaphoric words of Nirvana Sea is as follows.

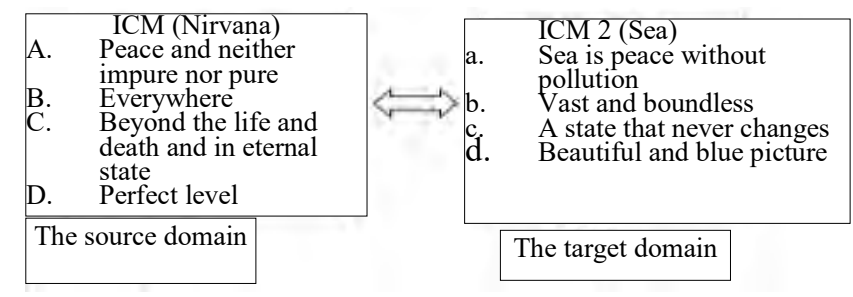

Fig. 1. Analysis on metaphorical mode.

As shown in "Fig. 1", through the thinking process of people's brain, the ICM models of Nirvana and Sea can be analyzed. Mapping their CM to each other to activate the relevant information of the thinking, which makes the key information of Nirvana and Sea can be reflected. According to the prominent information and the background information in people's brain, the information of metaphor of Nirvana Seacan is more clear understanding to highlight characters of beauty, quiet, endless, etc in the nirvana. LU Cheng pointed out that nirvana in reality has two main points: one is that nirvana is beyond the circulation of birth and death; the other is that nirvana must never stop in order to achieve the reality. ${ }^{13}$ Concepts are formed through the body, brain, and experience of the world. (Lakoff, 1999) metaphorical thinking process reflects the way humans' cognize the world. The ICM model contains several CMs, each of which is an aspect of the cognitive model. In the mapping relationship between metaphors, some CMs are strengthened and highlighted, which are Typical Categories in cognition. According to the principle of prominence, people's attention is easier to observe and remember typical and prominent aspects of things. ${ }^{14}$ The cognitive categories

11 Zhao Yanfang, A Survey of Cognitive Linguistics [J], Journal of PLA University of Foreign Languages, in the year of 2000, the fifth issue.

12 Wang Yin, Linguistics Frontier from the Perspective of Postmodern Philosophy — Experiencing Human-center and Cognitive Linguistics, Journal of Shanghai International Studies University, in the year of 2012, the sixth issue.

13 Fang Litian, Buddhist Philosophy, China Renmin University Press, Page 99

14 Zhao Yanfang, An Introduction to Cognitive Linguistics [M], Shanghai Foreign Language Education Press, in the year of 2009, Page 99 of all things are also conceptually proto-oriented. The Nirvana ICM model can be analyzed as follows.

- Nirvana ICM is also called Nivarna, Lucifer-Nirvana, Nibbana and Nirvana.

- Including Mie, Ji, Jimie, Jijing, Miedu, which is translated as Yuanji (Death of monk) by Xuanzang

- The highest level of the Buddhism

- Multifaceted content, Mahayana Mahaparinirvana Sutra lists 25 kinds and Catursatya Theory lists 66 kinds of variant name

- Achievement requires long time of training.

- Extinguish the cycle of life and death, no suffering, beautiful and quiet.

- Beyond the realm of time and space as the truth level, with not born nor die.

In 1980 George Lakoff and Mark Johnson co-wrote the Metaphors We Live By which points out that metaphor is not only a rhetorical means but also a way of thinking. The word of Nirvana is rich in meaning, and its meanings are multifaceted, complex and abstract, just like the members of a large category. In the spread and teaching of Buddhism, monks must visualize and materialize the abstract words so that the general public can quickly accept them, and even those at the bottom of the literacy level can understand and convert to internal religion. The use of argot, according to the principle of similarity and the principle of prominence, highlights the most important and core typical meanings in the meaning of Nirvana, such as "beauty and tranquility, beyond the life and death, and absence of suffering", so as to be accepted by the public. Just as in the book of Wei Shu - Shi Lao Zhi: "Nirvana is translated as Miedu, the final goal of learning Buddhism is the Nirvana; people who learn the Buddhism shall figure it out and nerve to ignore it." This metaphoric process can also be regarded as psychological coherence. That is, people recognize the world knowledge based on the information provided by sentences and their own inherent knowledge, and combine context to supplement relevant information. ${ }^{15}$ Another example is the metaphoric word of Treasure Medicine. The analysis of its ICM is as follows (as shown in "Fig. 2").

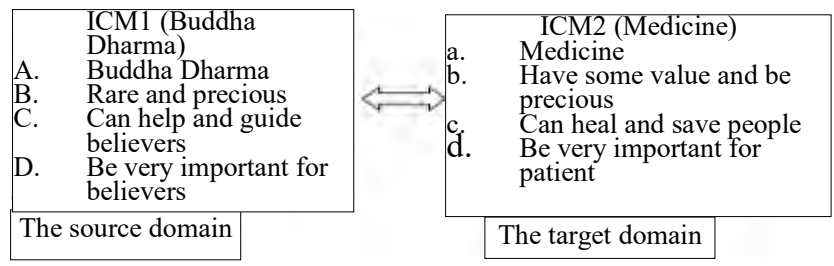

Fig. 2. Analysis on metaphorical mode (II).

In the metaphorical mapping of Treasure Medicine, CM aspects such as "can help and guide believers", "rare and

15 Liu Jia, Textual Coherence Studies from the Perspective of Cognitive Linguistics, Shanghai University Press, in the year of 2008, Page 110 
precious" and "be very important for believers" are highlighted. According to ICM model, we can list the CM of Buddha Dharma, such as

\section{Buddha Dharma ICM}

- The dogma and regulations of Buddhism

- Buddha said the dharma, there are eighty-four thousand dharmas

- The truth of the dharma realm is the supreme truth

- Including Mahayana Dharma, Hinayana Dharma and so on

- The Buddha has the power to save all living beings

- Dharma possession refers to the Tathagata's possession, which is the truth itself.

- Buddha Dharma life refers to the commandment the Buddha said; if the commandment is in the world, the Buddha Dharma does not die.

- Buddha Dharma is rare, solemn, holy and pure

It can be seen that the words of Buddha Dharma in ICM contains numerous CM models, some of which are typical $\mathrm{CM}$, such as "rare, solemn, holy and pure" and "Buddha has the power to save all living beings"; and some are atypical and marginal CM, such as "including Mahayana Dharma and Hinayana Dharma". In order to realize the communicative intention of Buddhism, Buddhist monks should use the words of Buddha Dharma to extract relevant typical concepts, highlight important factors, and express the key points that the speaker wants to emphasize. For example, it highlights the important function of Buddha Dharma, which has the power to cure the masses, free people from suffering and achieve nirvana. As master Yin Shun said, religion gives comfort to those who are in disappointment or sad, whether it is for fame, wealth or love, and gives healing to their wounds to make them strong. This is not opium, but a necessary nutrient to sustain life. ${ }^{16}$ The Saddharmapundarika Sutra - Foreword said, "The bright dharmas enlighten all living beings." Aparimitayur Sutra said, "The dharma with light will spread on and strengthen the public." Metaphoric language is characterized by transcending logical deduction and objectivity, which is manifested in the choice and arrangement of the information expressed. Everything is an entirety, but language expression is not complete and continuous, it can only select important, typical and relevant information. The rest of the information is made up by the listener's thinking. Through ICM analysis of Nirvana Sea and Treasure Medicine, we can clearly feel the structural network formed by the mutual mapping of metaphoric words. In the process of understanding, "in a certain context, a single hint may be

16 Yin Shun, My View to the Religion, Zhonghua Book Company, in the year of 2014, Page 16 enough to make the listener suddenly understand." This is also the understanding of convergence. ${ }^{17}$

\section{ANALYSES FOR METAPHORIC WORDS}

There are many metaphoric words in Dunhuang's Buddhist songs and lyrics, most of which are derived from Buddhist books or Buddhist principles, and most of them are not the first appearance in Dunhuang songs and lyrics. These metaphors not only show rhetoric, but also need psychological thinking and speculation. Saussure (2017) said that language is a symbolic system for expressing ideas, and this symbolic science will form a part of social psychology as well as a part of general psychology. ${ }^{18}$ That is very true. Metaphor represents the interactive thinking in psychology, as in the following examples.

\section{- Nirvana City}

The Five Changes: "at the beginning of the first change, to see the truth in nirvana city, delusion is empty and not real." Buddhism Dictionary: (apadana) Nirvana is the dwelling place of the holy one, so its apadana is imperial palace. Buddhist literature, such as Mahaprajnaparamita Upadesha Twenty said: "the dharma reality is nirvana city, and the city has three gates: empty, no phase, no action." The lyric compares Nirvana to a city, which embodies and visualizes the ultimate Buddhist ideal of Nirvana and makes people feel reachable. This metaphor is similar to the Citied Materphor in the Saddharmapundarika Sutra. This city does not exist, god changed and exists, so the name "Hua City" is Citied $^{19}$. The city metaphor for nirvana, in nirvana cognitive domain, mainly highlights the CM models, such as "resist the enemy of life and death, prevent wrong thinking, and guide all living beings". Through the interactive mapping of the two cognitive domains of Nirvana and City, the characteristics of "defending life and death and guiding all living beings" in the concept of nirvana are highlighted, which enhances its image and can infect believers to a greater extent.

\section{- Buddhist Sun}

The metaphor of Buddhist Sun gives people the feeling of being tall, spectacular and beyond the general. From the perspective of religion, this is the "superhuman's power". One of the fundamental characteristics of religion is that "its beliefs, behavioral patterns and values are all related to the existence of 'superman"'. Anthropologist Spiro defined religion as: "religion is a system composed of culturally prescribed interactions with culturally prescribed superhuman beings." ${ }^{20}$ Such beings include "superhuman

\footnotetext{
17 L. R. Palmer, Introduction to Linguistics [M], The Commercial Press, in the year of 2016, Page 91

18 Ferdinand de Saussure, Course in General Linguistics [M], The Commercial Press, in the year of 2017, Page 24

19 Hong Xue, Buddhist Literature of Chinese Language Family [M], Bashu Book, in the year of 2006, Page 65

20 Sun Shangyang, Religious Sociology, Beking University Press, in the year of 2015, Page 63
} 
forces, divine universes and transcendent realities". ${ }^{21}$ Engels also pointed out in the Anti-Duhring that "all religions are just the reflection of the illusion of external forces in people's minds, and the human forces take the form of superhuman forces". ${ }^{22}$ Not only the Buddhist Sun, but also Nirvana Sea and so on, has given the believers with a powerful, spectacular feeling. The Buddha is also known as Vairacana, which originally contains the meaning of bright and shining. The name of the Buddha "is the result of the Mahayana Sutra's metaphor of the Buddha as the sun shining on all and giving birth to all". ${ }^{23}$ This metaphor "the Buddha is the Sun, the illuminator of the world and the source of the world from the doctrine." (Hong Xue 2006)

\section{- Creeping Disease}

The Five Changes - Nanzong Divids Evil and Good: "the great circle mirror is put there, all beings can not have creeping disease, so the heart is closed for the barriers." Creeping, Buddhism said it is a kind of situation, because the mind is not quiet and changed with the external factors. Creeping is derived from the Sanskrit of alambana. The Buddhism Dictionary: "(terminology) the heart is not alone, must have the right environment, creeping to the other. Just like an old man's creeping rod, it is called creeping. Buddhism believes that Creeping is a delusion and will cause trouble, in this sentence "creeping disease", Creeping is compared to disease. Palmer points out that language is a series of hints from which the listener has to construct the speaker's intention, and those hints are explicit or implicit. ${ }^{24}$ By saying Creeping as a disease, the disadvantages of Creeping for Buddhist practice are highlighted. The believers perceive the similarity on which this metaphor is based and understand it more deeply. This process is often accomplished automatically through what psychologists call synaesthesia. W ${ }^{25}$ ANG Yin (2015) concluded that metaphor is not a rhetorical phenomenon in nature, but a cognitive activity, which plays an important role in the formation of human categorization, conceptualization and thinking reasoning. In the human brain thinking, the two concepts of Creeping and Disease are mapping to each other and form a mixing result.

\section{- Reward Field}

The Five Changes - Nanzong Praise: "all Buddhism, execute reward field, abstain from meat, wine, etc., go to heaven." Buddhism believes that good deeds can be rewarded by virtue and goodness. It is like sowing a field that yields good fruit. The Buddhism Dictionary: "the growth of the field for righteousness, should provide for those who provided for, and those will be able to receive

\footnotetext{
21 Sun Shangyang, Religious Sociology, Beking University Press, in the year of 2015, Page 63

22 Selections of K. Marx and F. Engels, People's Publishing House, in the year of 2012, the third volume, Page 354

23 Hong Xue, Buddhist Literature of Chinese Language Family [M], Bashu Book, in the year of 2006, Page 82.

24 L. R. Palmer, Introduction to Linguistics [M], The Commercial Press, in the year of 2016, Page 85

25 L. R. Palmer, Introduction to Linguistics [M], The Commercial
} Press, in the year of 2016 , Page 85 various blessings, just as the farmer sows in the fields, there are autumn harvest benefits." Other literature, such as Jin Dao Heng's Explanation and Refutation Theory: "to know the three respects is support by all living beings in reward field, which is self-cultivation of their own." Reward Field is to receive blessings through dedication, just like the general farming. That belongs to the concept of karma and reincarnation advocated by Buddhism, such as the "twelve causes". That metaphor clearly reflects the ideal of believers in life. This is the relationship between ideal and religion, which is the expression of human's own will and the environment. Inequality asks for equality, illiberality for liberty, inconstancy for eternity, and folly for wisdom. ${ }^{26}$ When oppressed and suffering in the real world, people hope to be blessed in the future and in the afterlife. SUN Shangyang, an academic, pointed out that religion "remains the ultimate resource for all people to seek comfort and hope. It once and still regulates and guides the words and deeds of most people and provides them with a picture of the world". 27

\section{- Ignorance Quilt}

Difficult to Walk on the Road: "living beings are greatly foolish, refused to, such as clothes, often lie with ignorance quilt. The Buddhism Dictionary: "Ignorance, (the jargon) Sanskrit of Avidy \& amacron, which means that the heart of darkness and dullness is not enlightened by the laws and principles and is the variant name of the fool." According to Buddhism, Ignorance prevents people from seeing the fundamental power of reality in the world and is also the source of attachment and greed and hatred. FANG litian pointed out that the most fundamental thing in ignorance is the inability to understand the nature of causation - the absence of constancy and the absence of self. ${ }^{28}$ Quilt is wrapped around the body to keep warm. Ignorance and Quilt are linked, and the ignorance is compared to the quilt, highlighting the people are wrapped by ignorance. Richard (1936) first proposed the theory of metaphoric interaction, in which two different ideas are put in juxtaposition and can interact. Whorf (1939) pointed out that if we do not rely on the metaphor of materiality, we can hardly talk about the simplest non-spatial situation. ${ }^{29}$ Sweetser (1990) believes that metaphor enables people to understand one thing as another, regardless of whether the two are objectively the same. ${ }^{30}$ The interaction between Ignorance and Quilt makes the concept of Ignorance clear, and through thinking process of brain, the significance of "wrapping around the body" increases. The process of understanding is to find unity in contradiction, change difference into same, and get meaning

\footnotetext{
26 Yin Shun, My View to the Religion, Zhonghua Book Company, in the year of 2014, Page 6

27 Sun Shangyang, Religious Sociology, Beking University Press, in the year of 2015, Page 1

$28 \quad$ Fang Litian, Buddhist Philosophy [M], China Renmin University Press, in the year of 1997, Page 82.

29 Wang Yin, Cognitive Linguistics [M], Shanghai Foreign Language Education Press, in the year of 2015, Page 403

30 Wang Yin, Cognitive Linguistics [M], Shanghai Foreign Language Education Press, in the year of 2015, Page 403
} 
from the same. This thinking process is a cognitive mode or reasoning mechanism.

\section{- Moksha Paddle}

Empty without Master: "when it stops, at Nirvana Sea with moksha paddle, like prajna cool without the troubles." New Buddhism Dictionary: "Moksha, the free translation of Sanskrit of vimukta, which means the freedom from the bondage of troubled karmic obstacles." The basic contents of the Buddhism Dharma are the four noble truths, the noble truth of suffering, the noble truth of reason, the noble truth of destruction and the noble truth of road. ${ }^{31}$ The four noble truths are all related to suffering, "birth is the beginning of suffering, and life is the object of suffering, so try to not suffer 'suffering"'. ${ }^{32}$ The solution to suffering is the moksha, or nirvana. This metaphor combines Moksha with Paddle and is based on the metaphor of "life is a sea of suffering, nirvana is on the other side". This metaphor has a certain tension, highlighting the suffering of life, and showing the fact that "moksha depends on yourself", as long as the effort to paddle, life can reach the other side. This also reflects the effects of metaphor. Palmer points out that what makes a metaphor special is the tension between literal meaning and symbolic meaning. ${ }^{33}$ This connection between abstraction and concreteness lets the believers have some associations that symbolic language makes use of, especially to describe mental states. 34

\section{- Diligence Horse}

Difficult to Walk on the Road: "the body does ride the diligence horse, endure humiliation as the saddle." Mr REN recorded the original text, omitted the "horse" of "diligence horse ", following Xiang Chu's opinion to change. ${ }^{35}$ This kind of apadanas is common in Buddhism. In the Mahaprajnaparamita Upadesha: "the Buddha uses endurance as his armor, diligence as his armor, abstinence as his horse, and meditation as his bow." "Diligence" is one of the "six paramitas" in Buddhism, which means "to execute good and break evil, to abandon dyeing and turn to purity... in the process of cultivation, we should make unremitting efforts, never retreat bravely and never fear difficulties." ${ }^{36}$ The requirement of diligence progress is that "even there are the poison of soup and fire and the harm of blade and poison", but also "being glad to help the difficult others" and never retreat. ${ }^{37}$ Fang Litian also pointed out that progress refers to "unremitting efforts, never retreat, really

31 Zhao Piaochu, The Relationship Between Buddhism and Chinese Culture, Zhonghua Book Company, in the year of 1997, Page 4.

32 Du Jiwen, How to Understand the Buddhist's Outlook on Life and Morality [M], Zhonghua Book Company, in the year of 1997, Page 24

33 L. R. Palmer, Introduction to Linguistics, The Commercial Press, in the year of 2016, Page 85

34 L. R. Palmer, Introduction to Linguistics, The Commercial Press, in the year of 2016, Page 86

35 Xiang Chu, Checked Summary of Dunhuang Songs and Lyrics, Bashu Book, in the year of 2000, Page 129

36 Chen Bing, New Buddhism Dictionary, China EsperantoEldonejo, in the year of 2003, Page 60.

37 Du Jiwen, How to Understand the Buddhist's Outlook on Life and Morality [M], Zhonghua Book Company, in the year of 1997, Page 28. do not tire of learning." ${ }^{38}$ Metaphor is to "project from one cognitive domain to another". "Diligence horse" projects the abstract concept of "diligence" into the general domain of "horse", which highlights the characteristics of "diligence" and emphasizes that practitioners should go forward bravely and not be afraid of difficulties. This is also a spur to the believers, urging them to work hard to repair.

\section{- Compassion Net}

Empty without Master: "wish to cover the compassion net, ask all people in glory house." "Compassion" is a Buddhist concept, CHEN Yixiao explained in the Common Vocabulary of Buddhism: "compassion and compassion. May peace and happiness be called kindness to all living beings. May the suffering of all sentient beings be called grief. "Compassion" is one of the "kindness, compassion, joy and sacrifice" in the four boundless hearts of Buddhism. 39 "Compassion net" compares "compassion" to a net, which means to bring things into one's compassion. The metaphor of compassion network vividly expresses the beautiful religious ideal. All noble religions take freedom, equality, happiness and compassion as their ideals. ${ }^{40}$ Not only compassion, but good religious feelings range from fleeting moments of peace and awe to extraordinary mystical experiences. It may include aspects of happiness such as peace, harmony, joy, abundance, and security. ${ }^{41}$ (SUN Shangyang, 2015) the mutual mapping of "compassion" and "network" shows the compassion, vastness and omnipresence of Buddha Dharma.

\section{- Life and Death Root}

Difficult to walk on the Road: "do you realize that the only way to fall is to get lost, which is the deeper root of life and death. Buddhism is unique in the concept of "life and death". Buddhism believes that all living beings are born and die in the cycle of samsara, and that they are born and died again and again in the three realms and the six paths. ${ }^{42}$ Buddhism advocates that the purpose of religious practice is to break away from the six paths of samsara, get rid of life and death, achieve nirvana and realize moksha. And the state of nirvana, the highest ideal of Buddhism, is not to be born or died, to be free from the agony of life and death, to be happy forever. As Jin monk Zhao's Nirvana Nameless Theory: "the path of nirvana is the finial station of the three vehicles, such as the deep mansion. Life and Death Root compares "life and death" to "root", emphasizing the deeprooted "life and death". This metaphor has a profound impact on the audience. The myth of creation and rebirth, the values of good and evil and these less formal beliefs are

\footnotetext{
38 Fang Litian, Buddhist Philosophy [M], China Renmin University Press, in the year of 1997, Page 126.

39 Li Yingwu, Three Classics of Zen [M], Bashu Book, in the year of 2008, Page 358

40 Yin Shun, My View to the Religion, Zhonghua Book Company, in the year of 2014, Page 17

41 Sun Shangyang, Religious Sociology, Beking University Press, in the year of 2015, Page 72 .

42 Chen Bing, New Buddhism Dictionary, China EsperantoEldonejo, in the year of 2003, Page 77
} 
often more influential than systematic ideological beliefs on the behavior of believers. ${ }^{43}$

\section{- Eros River}

Back and forth: "pull all living beings out of Eros River, out of Eros River." Buddhism considers "eros" as a sea of suffering, which makes people degenerate and fall into six cycles. In Eros River, eros is compared to a river, and the meaning of river is "indulgence and danger". These words were first seen in Flower Ornament Sutra translated by the Tianzhu Sanzang Buddha of Tuobaluotuo in the Eastern Jin Dynasty: "with the flow of life and death, enter the great eros river; they are fed by the forces of trouble and cannot find out what they want."Eros River" was included in the Great Dictionary. The documentary evidence is the translation of the Surangama Sutra vol. 4 in the Tang Dynasty: "Eros River dries up. Time is too late. From the perspective of language expression, this metaphor is the original creation of Buddhism with freshness, which is the psychological basis of metaphor. "People have been tired with one issue all the time, but it there is an allusive issue which required imagination and thinking, he would feel excited" ${ }^{44}$ Novel metaphors work better than dull moralizing.

\section{- Mara Army}

The Five Changes: "there is no space inside, outside or the middle, the mara army will die and can not invade. The mara is a Sanskrit word and can be called the devil. The "mara army", which compares the power of maras to a powerful army, shows the power of maras, which makes practitioners deeply alerted. Feuerbach pointed out that there is certainly an elf in nature from the standpoint of faith, but that elf is the spirit of man, man's fantasy or man's mood. ${ }^{45}$ Indeed, the so-called mara of religion is actually the product of mental thinking in the brain, but this kind of mara makes believers alerted and afraid. Believers believe that "soul, ghost and mara work on people in some situations at least." ${ }^{46}$ Chen Bing, New Buddhism Dictionary: "maras can hinder and destroy all kinds of factors for people to study Buddhism and so on." ${ }^{47}$ Mahaprajnaparamita Upadesha: "take the life of wisdom and harm the dharma, merit and virtue, which are called the maras. Volume 9 of the Shurangama Sutra states some mara things during the meditation in details. The two cognitive domains of "mara" and "army" are superimposed. This metaphor can form thousands of images of maras in the brain and render the horror of maras.

\section{ANALYSES FOR EFFECT OF METAPHOR}

Metaphor refers to the use of one concept to express another concept, which is based on the principle of similarity. In metaphor mapping, the correlation between these two concepts is required. This correlation and interaction can express "things that cannot be expressed by human perception itself". There are many studies on the expression effect of metaphor and metaphorical words in the academic world. The use of Buddhist metaphors has a good effect on the spread of Buddhism. Zhang Haisha summed up the three functions of the apadana of Buddhist books, which are, the wisdom of the Buddhas is very deep, convenient to say; the other is to say the Buddha dharma skillfully, which makes all living beings happy; the third is to make all living beings understand the Buddha Insight and get rid of lost and mistakes. ${ }^{48}$ This paper focuses on the analysis of the Buddhist aesthetic image created by the metaphors of Dunhuang Buddhist songs and lyrics. The characteristic of Buddhist aesthetics is very rich, this paper mainly talks the aesthetic characteristics manifested by metaphor of songs and lyrics.

The first is the sublime and spectacular. Aesthetically, tall mountains, rivers and buildings can bring lofty, majestic and spectacular feelings. At the same time, it can give people a psychological shock, a great pressure on the power. Psychologically, such a height can make people fear, fear, and then the worship of god. ${ }^{49}$ The human will in higher religions is not only the purification of the mind, but also its own perfection. Such as Buddhism, not only the dharma body of grief and wisdom solemn, but also the color of the body of harmony. ${ }^{50}$ Buddha cadastral, all kinds of dharma enlarged metaphor is more, such as song ci "nirvana shadow of the sea, nirvana city, five mountain, mountain, seven sea, month, day, sea, intelligence, wisdom, city, sunburst (refers to the Buddha dharma)" and so on, this kind of metaphor, with magnificent appearance and splendor of the ocean, mountains, sun, sun, towers, etc to refers to the dharma, nirvana, and wisdom, foil the dharma of great and noble. ZHANG Zuobang believes that the dark in the tall Buddha, the solemn Buddha light, and people feel the sacred great Buddha, benevolent. ${ }^{51}$ At the same time, Buddhist temples are grand in construction, beautiful in decoration and resplendent in color, which can also make believers feel the sanctity of Buddhism. "All the wooden structures to the ceiling are colorful and resplendent, which makes the worshippers firmly believe in the beauty of the paradise on the other side of the west and naturally produce the psychological illusion of longing for the Buddhist country."

\footnotetext{
48 Zhang Haisha, Apadana: Convenient Transmission and Poetic Expression for Buddhism [J], Chinese Social Sciences Today, on June, 2014.

49 Ludwig Andreas Feuerbach, The Nature of Religions, The Commercial Press, in the year of 2009, Page 8

50 Yin Shun, My View to the Religion, Zhonghua Book Company, in the year of 2014, Page 14

51 Zhang Zuobang, The Influence of Religious Artifacts on Human Aesthetic Psychology [J], Guizhou Social Sciences, in the year of 2008, the fifth issue
} 
${ }^{52}$ MA Delin also pointed out that ancient religious architecture took the external volume characteristics as the symbol of divinity, and the huge volume gave people visual surprise. (1987:103) That nobility inspires awe and induces the worship and conversion of believers. ${ }^{53}$ This sublime reflected fully in the Christian church, ancient Pyramids of Egypt, Greek Temples and other buildings.

The second is kindness and love. Socrates believes that the difference between god and man is that god is always good. Feuerbach also pointed out that compassion is the fundamental characteristic of the gods. ${ }^{54}$ Schleiermacher, a religious aesthete in the 19th century, pointed out that human emotion towards religion contains an absolute sense of dependence on religion. The "benevolence" of Buddha is the emotional basis for believers' dependence on Buddhism. Buddha statue, such as the elegant and fat of Maitreya, just is the ideal type of our people. When Avalokitesvara Bodhisattva is believed by the ordinary women, the Bodhisattva gradually shows a gentle, kind and tolerant female appearance. ${ }^{55}$ In Buddhist songs and lyrics, such as the Dissonance Name, "the Buddha cherishes all living beings, and the mother pities men and women; a case of kindness is from the beginning of love; The Buddha is like a mother without differences in meaning, the mother is like a Buddha with praise in heart. Those metaphors, such as "Buddha is like a mother" and "mother is like a Buddha", add a kind aura of compassion to the Buddha, which attract believers with emotion and make ordinary believers have a motherly dependence on the Buddha emotionally. Similar metaphoric words also include "treasure medicine" and "dharma king", such as the sentence in Pleasure of Monasticism: "hair, body and mind, in accordance with the holy study, in addition to the knot to make a gold knife; shave hair, dress in clothing and eat treasure medicine. To compare the Buddha dharma as a treasure medicine what can heal the soul trauma of believers. In Inaction Proof . Happy of Return: "understanding can bring the return a happy, live in the house of the dharma king." The metaphor of "dharma king" also depicts the brilliant and benevolent image of Buddha, which can induce believers to convert. Such metaphors have shaped the Buddha's "ideal state of gentleness, kindness and kindness", such as the Six Paramitas Sutra and other apadana stories. "In many places, Sakyamuni's benevolent mind and altruistic spirit are written". ${ }^{56}$ "This kind of level is actually a strong contrast to the tragedy of the world and the difficulties and suffering of indifferent life." (MA Delin, 1987) the image of the benevolent Buddha can unite believers, stimulate religious feelings of believers, and make people of different classes

52 Zhang Zuobang, The Influence of Religious Artifacts on Human Aesthetic Psychology [J], Guizhou Social Sciences, in the year of 2008, the fifth issue

53 Ma Delin, Religion, a Cultural Phenomenon [M]. Shanghai People's Publishing House, in the year of 1987, Page 101

54 Ludwig Andreas Feuerbach, The Nature of Religions [M], The Commercial Press, in the year of 2009, Page 66

55 Yin Shun, My View to the Religion, Zhonghua Book Company, in the year of 2014, Page 6

56 Hong Xue, Buddhist Literature of Chinese Language Family [M], Bashu Book, in the year of 2006, Page 65 and levels of education generally accept it. Religion is the product of human wisdom and a special manifestation of human ideals. ${ }^{57}$ In the final analysis, that is the ideal of human beings. This ideal, which comes from the suffering of the real world, is Marx's view of religion as a kind of supplement or disguise to the sanctification of this inverted world, and a moral approval. It is a kind of comfort or psychological compensation for the individual who has lost himself or the unprivileged. ${ }^{58}$ Marx's religious view had a profound influence on Weber, Berger, Turner and other religious sociologists.

The third is the concept of life and death. In the Dunhuang Buddhist songs and lyrics, "life and death" are frequently used, appearing 76 times in total, which clearly shows the importance of life and death to Buddhism. The issue of life and death has always been the fundamental issue that all religions must face to solve. One of the reasons why religion can become people's belief is that it contains the ultimate commitment to solve the problem of death. The core of the Buddhist concept of life and death is to understand life and death, break life and death, and allow life and death. ${ }^{59}$ Master Yin Shun said, Buddhism says that there is no life, which is a deeper level than the general religion, a complete denial of the pain and discomfort of the feelings of the mixed nature, and a realization of infinite happiness and free wisdom to get the pure life. ${ }^{60}$ Madhyamaka Shastra: "the law of life of many is caused by the faith; what I say is empty, a pseudonym, and the moral." Buddhism believes that the human body is the four great harmonies, and the body is false and empty like stinking skin-bag. In life and death, people have to go through the painful samsara with three circles and six paths. Hell, evil spirits, animals and Asura belong to the evil path. Entering that kind of path, people have to go through great pain and suffering. Only the human and heaven is good path. The samsara theory of Buddhism gives people the courage to face death, death is not terrible. Nirvana is the direct answer to the question of life and death. About overcoming the problems of life and death, Abe Masao said: "the fundamental thing is to be liberated from the contradiction between life and death, and realize to break away from the circle of life and death. ${ }^{61}$ Some metaphoric words are in Buddhism such as "river of life and death".

The Five Changes and twelve, Weimotuo Disease: "turbulent waves clear and net the sea, never backflow to river of life and death, farewell to mud and seek for love."

The term "life and death" is compared to a river. The river floods everything. The cycle of life and death also

\footnotetext{
57 Yin Shun, My View to the Religion, Zhonghua Book Company, in the year of 2014, Page 16

58 Sun Shangyang, Religious Sociology, Beking University Press, in the year of 2015, Page 69

59 Zhu Zhixian, A Brief Discussion of Buddhism's View of Life and Death [J], Theory Monthly, in the year of 2007, the eighth issue

${ }^{60}$ Yin Shun, My View to the Religion, Zhonghua Book Company, in the year of 2014, Page 18

61 Zhu Zhixian, A Brief Discussion of Buddhism's View of Life and Death [J], Theory Monthly, in the year of 2007, the eighth issue
} 
rules the three realms and the six paths, and human beings can not get rid of the cycle of life and death. This metaphor promotes Buddhism's idea of "cycle of life and death, suffering" and highlights the characteristics of "omnipresent and boundless" of life and death. Another example is in "Xitan Ode · Custom Chapter of Xitan", "every followers of Buddha do not be lazy, you have come to live in the dark room without beginning. You can not go out of life and death, cause the fool and lost obstruct the wisdom", "Difficult to Walk the Road · Live Together in the Monastery", "living beings are often bound by beauty and money, falling into Eros River and sinking in life and death. Life and death are troubling human beings. Since the cycle of life and death is so painful, we have to take nirvana to get rid of life and death and reach the other side. That is the purpose of Buddhist cultivation, such as the sentence in Seeking Cause and Effect · Practice Goodness, "samsara is trouble, so to be bodhi, life and death will separate from the Avici Hell", Empty without Master: "when to meet the Prajna ship, pontoon bridge on life and death river, come to enjoy, all the troubles leak out". Breaking away from the river of life and death and reaching the other side just realize the Nirvana. This is also the charm of religion. Self-religion, human beings are asking for eternal life, happiness, equality, freedom, wisdom and compassion. ${ }^{62}$ Some similar metaphoric words, such as "the earth of life and death, the sea of life and death and the root of life and death", in the songs and lyrics, refer to "life and death" as "the earth, the sea and the root", and also highlight the view that "life and death are everywhere and firm as roots in Buddhism, urging believers to convert to Buddhism and release from life and death. On the other hand, it also shows the view that "life and death are common things", which has a certain psychological comfort effect on believers to overcome the fear of death, such as the sentence in Dissonance Name - See the Truth, "life and death are common things, see him alive, see you die, and look at myself in the same way". This religious power can enhance people's psychological strength to a certain extent. Religion causes humans to be strong in their own power, and to be very powerful. Let people strengthen themselves to overcome difficulties and purify themselves to the level of the highest good from their faith. ${ }^{63}$

\section{CONCLUSION}

From the perspective of rhetoric, using metaphor can make the language vivid and concise. The core of metaphor is to understand the experience in one field by using experience in another field. Metaphor is not only a linguistic phenomenon. In essence, metaphor is a tool for human beings to understand the perception to external world and form a concept. In the spread of Buddhism, the use of metaphors highlights the core concept of Buddhism, gets the abstract Buddhist principles linked with the surrounding world that we can perceive by the senses and visualizes the concept of Buddhism, such as "Life and Death Root, Trouble River, Nirvana Tower". Those metaphors can effectively attract believers. The metaphor highlights the Buddhism's "beautiful, sublime" and "compassionate" and "able to make believers out of suffering" images.

\section{REFERENCES}

[1] Ma Delin. Religion, a Cultural Phenomenon [M]. Shanghai People's Publishing House, in the year of 1987, Page 105. (in Chinese)

[2] Hong Xue. Buddhist Literature of Chinese Language Family [M], Bashu Book, in the year of 2006, Page14. (in Chinese)

[3] Zhao Yanfang. An Introduction to Cognitive Linguistics [M], Shanghai Foreign Language Education Press, in the year of 2009, Page 99. (in Chinese)

[4] WEN Suolin. The Existential Sentences to Cognitive Basis and Rhetorical Motivation of Spatial Metaphor, Shanghai University Press, in the year of 2008, Page 82. (in Chinese)

[5] Wang Wenbin. The Nature, Structural Types and Internal Relations of the Idealized Cognitive Models, Foreign Language Learning Theory and Practice, in the year of 2014, the third issue. (in Chinese)

[6] Zhao Yanfang. A Survey of Cognitive Linguistics [J], Journal of PLA University of Foreign Languages, in the year of 2000, the fifth issue. (in Chinese)

[7] L. R. Palmer. Introduction to Linguistics, The Commercial Press, in the year of 2016, Page 87. (in Chinese)

[8] Wang Yin. Linguistics Frontier from the Perspective of Postmodern Philosophy - Experiencing Human-center and Cognitive Linguistics, Journal of Shanghai International Studies University, in the year of 2012, the sixth issue. (in Chinese)

[9] Fang Litian. Buddhist Philosophy, China Renmin University Press, Page 99. (in Chinese)

[10] Liu Jia. Textual Coherence Studies from the Perspective of Cognitive Linguistics, Shanghai University Press, in the year of 2008, Page 110. (in Chinese)

[11] Yin Shun. My View to the Religion, Zhonghua Book Company, in the year of 2014, Page 15. (in Chinese)

[12] Zhang Zuobang. The Influence of Religious Artifacts on Human Aesthetic Psychology [J], Guizhou Social Sciences, in the year of 2008, the fifth issue. (in Chinese)

[13] Ludwig Andreas Feuerbach. The Nature of Religions [M], The Commercial Press, in the year of 2009, Page 66. (in Chinese)

[14] Yin Shun. My View to the Religion, Zhonghua Book Company, in the year of 2014, Page 16. (in Chinese)

[15] Sun Shangyang. Religious Sociology, Beking University Press, in the year of 2015, Page 69. (in Chinese)

[16] Zhu Zhixian. A Brief Discussion of Buddhism's View of Life and Death [J], Theory Monthly, in the year of 2007, the eighth issue. (in Chinese)

[17] Zhu Zhixian, A Brief Discussion of Buddhism's View of Life and Death [J], Theory Monthly, in the year of 2007, the eighth issue. (in Chinese)

[18] Cao Yan. A Study of See's Metaphorical Collocation, Shanghai University Press, in the year of 2008, Page 68. (in Chinese)

[19] Wang Yin. Cognitive Linguistics [M], Shanghai Foreign Language Education Press, in the year of 2015, Page 469. (in Chinese)

[20] Zhang Haisha. Apadana: Convenient Transmission and Poetic Expression for Buddhism [J], Chinese Social Sciences Today, on June, 2014. (in Chinese)

\footnotetext{
62 Yin Shun, My View to the Religion, Zhonghua Book Company, in the year of 2014, Page 14

63 Yin Shun, My View to the Religion, Zhonghua Book Company, in the year of 2014, Page 15
} 